Editorial

\title{
Changing the rules of the game
}

\section{Editorial}

Since two years ago I have the luck to be an editor of the magazine Dental Health, Oral Disorders \& Therapy. It has spent little time but today I feel proud to belong to a scientific structure that has given birth to more than 80 articles from researchers around the world.

From Spain, where I have my clinical practice and performance my teaching, I see with great satisfaction as the articles for the magazine I supervise, have a multidisciplinary and multinational character. I am convinced that this diversity in form and content of our magazine makes one of the most complete and serious industry and I invite you all to follow and promote it so that this project is open to everyone, will continue to grow.

The duty of the scientific community is asking questions, investigate and find approaches that lead to better solutions to the same problems. Since the magazine and the editorial MedCrave provides an opportunity for all professionals to continue to learn, to become better professional sector.

Our magazine is destined to become one of the industry benchmarks for their accuracy, reliability and detail and also for having bet on the spread and not to the exclusion of other scientific journals do their flag.

Then congratulate ourselves for this successful start and serve to motivate us even more in the performance of our profession, we continue learning, to continue investigating, we continue to improve and wanting to share it with our partners so that they improve with us.
Volume 4 Issue I - 2016

Daniel Carcamo del Rio

Department of Oral Surgery \& Pathology,Alfonso X el Sabio University, Spain

Correspondence: Daniel Carcamo del Rio, Department of Oral Surgery \& Pathology, Alfonso X el Sabio University, Spain, Email danicarcamo@hotmail.com

Received: December 18, 2015 | Published: January 9, 2016

And this magazine continues transmitting those values of cooperation and improvement and get, together, place it at the level it deserves.

\section{Funding}

None.

\section{Acknowledgements}

None.

\section{Conflicts of interest}

Author declares that there is no conflict of interest. 